\title{
Ethics in Mediation: Centralising Relationships of Trust
}

\author{
Susan Douglas
}

Revision of the National Mediator Accreditation System, effective from 1 July 2015, removes the requirement for mediators to demonstrate understanding of neutrality as an ethical competency. The principle of impartiality has been retained and the principle of self-determination has been newly included as an ethical competency. The self-determination of participants, recognised in the original version of the NMAS, has been more clearly articulated as the aim of mediation practice. Abandonment of the principle of neutrality signals a need to reconsider the role of the mediator, which was once identified with control of the process of mediation, though neutral as to its content and outcome. Abandonment of neutrality calls for an alternative frame of reference for ethical practice in mediation. In this paper, the relationship of trust between mediator and parties is proposed as a suitable and defensible alternative ethical framework. It is argued that this relationship can be constructed according to principles associated with fiduciary and therapeutic relationships, in recognition of the distinctive socio-legal context of practice. Abandonment of neutrality also raises issues as to the mediator's role in achieving fairness for participants. It is argued that relationships of trust provide a convincing framework within which to consider issues of substantive fairness in mediation.

\section{INTRODUCTION}

Revisions to the National Mediation Accreditation System (NMAS), effective from 1 July $2015,{ }^{1}$ signal changes to our traditional understanding of mediation and the role of the mediator. Two specific changes demonstrate a significant shift in understanding. First, reference to the neutrality of the mediator has been omitted from the standards. Neutrality was once a defining characteristic of the role of the mediator. ${ }^{2}$ An understanding of neutrality was also an ethical requirement for practice, according to the original NMAS established in 2007 (effective Jan 2008). ${ }^{3}$ This change arguably reflects sustained critique of neutrality in mediation. ${ }^{4}$ Secondly,

1 Mediator Standards Board, National Mediator Accreditation System (NMAS) (1 July 2015) <www.msb.org.au/sites/default/files/documents/NMAS\%201\%20 July\%202015.pdf>.

2 See, for example, the definitions in Hilary Astor and Christin Mary Chinkin, Dispute Resolution in Australia (Butterworths, 2nd ed, 2002) 83; Laurence Boulle, Mediation: Principles, Process, Practice (Butterworths, 2nd ed, 2005) 4.

3 National Mediation Accreditation System (NMAS), Practice Standards (2007) cl 7(c)(iv).

4 The reasons for omission of neutrality in revisions of the NMAS have not been published. For a critique of neutrality see, for example, the seminal work of 
understanding of self-determination has been inserted as an ethical requirement for practice and confirmed as a defining feature of mediation, ${ }^{5}$ now clearly described as a 'process that promotes the self-determination of the participants'. ${ }^{6}$

These changes pose challenges for understanding the role of the mediator. Neutrality was once the cornerstone of that role. ${ }^{7}$ When placed in the context of the facilitative model of practice, neutrality provided assurance, in theory if not in practice, of the self-determination of participants. Three interrelated principles were central to traditional understanding. According to the classic, facilitative model, mediation is understood as divided into process, content and outcome. ${ }^{8}$ The mediator was understood to be neutral in relation to the content and outcome of mediation but in control of the process. ${ }^{9}$ The mediator's control of the process assured procedural fairness for the parties. Self-determination was achieved by the parties' control of the content and outcome of mediation. The parties' control of the content and outcome ensured substantive fairness. Flaws in the logic of these interrelated principles became evident with growing awareness that mediators were not neutral in any absolute sense, ${ }^{10}$ that there were other ways of looking at the dynamic of mediation, demonstrated by other models, ${ }^{11}$ and that substantive fairness would not be assured where one party suffered a disadvantage in relation to the other party that could not be remedied by process, or procedural, interventions. ${ }^{12}$

Hilary Astor, 'Rethinking Neutrality: A Theory to Inform Practice - Part 1' (2000) 11 Australasian Dispute Resolution Journal 73; Hilary Astor, 'Rethinking Neutrality: A Theory to Inform Practice - Part 2' (2000) 11 Australasian Dispute Resolution Journal 145.

$5 \quad$ NMAS, above n 1, Pt 111, cl 10.1(c) (iii).

$6 \quad$ Ibid, Pt 111, cl 2.2.

7 See, for example, Hilary Astor, 'Mediator Neutrality: Making Sense of Theory and Practice' (2007) 16(2) Social and Legal Studies 221, 222; Rachael Field, 'Neutrality and Power: Myths and Reality' (2000) 3(1) The ADR Bulletin 16, 16; Nigel Polak, 'No Longer Neutral: Practitioner Power in Compulsory (Family) Dispute Resolution' (2009) 20 Australasian Dispute Resolution Journal 88, 89; Linda Mulcahy, 'The Possibilities and Desirability of Mediator Neutrality: Towards an Ethic of Partiality?' (2001) 10(4) Social and Legal Studies 505, 509.

8 Boulle, Mediation, 2nd ed, above n 2, 29-30; and for a more recent view see Laurence Boulle, Mediation: Principles, Process, Practice (Butterworths, 3rd ed, 2011) 43-48.

$9 \quad$ Astor and Chinkin, above $\mathrm{n} 2$.

10 Astor, 'Rethinking Neutrality', Parts 1 and 2, above n 4; see Susan Douglas, 'Mediator Neutrality: A Study of Mediator Perceptions' (2008) 8(1) Queensland University of Technology Law and Justice Journal 139,139-141.

11 See Susan Douglas, 'Neutrality, Self-determination, Fairness and Different Models of Mediation' (2012) 19 James Cook University Law Review 19; John Winslade and Gerald Monk, Narrative Mediation: A New Approach to Conflict Resolution (Jossey-Bass, 2000); Robert A Barusch Bush and Joseph P Folger, The Promise of Mediation: A Transformative Approach to Conflict (Jossey-Bass, revised ed, 2005).

12 See Rachael Field, 'Mediation Ethics in Australia: A Case for Rethinking the Foundational Paradigm' (2012) 19 James Cook University Law Review 41, 65-68. See particularly $66 \mathrm{fn} 165$ for a list of the author's papers in relation to this issue. 
Reassessment of what delineates the nature and scope of the mediator's role is needed given abandonment of neutrality in the NMAS. A revised understanding needs to encapsulate the essence of that role for all mediators, despite varying models and practice contexts. Scholars have suggested various ethical models to articulate that essence. The following discussion contributes to that endeavour by proposing that the relationship of trust between mediator and parties be adopted as a framework for ethical practice in mediation. The NMAS describes the knowledge, skills and ethical understandings required for practice. It is a premise of this discussion that relationships of trust provide an ethical framework for mediators' use of all three dimensions of practice, ${ }^{13}$ in other words, for any and all of the practice decisions and interventions they make.

Discussion is in six parts. The first part examines ethical frameworks for mediation developed or advanced by Australian scholars. ${ }^{14}$ The second part examines current ethical issues in mediation. The third part explores mediation and professional relationships and examines the relevance of trust in the relationship between mediator and parties. The following two parts examine fiduciary and therapeutic relationships as sources of ethical duties, obligations and principles that can be employed to shape an ethical practice for mediation. The final section concludes by bringing together principles from the preceding discussion to articulate the character of relationships of trust in mediation.

\section{A Review of Existing Ethical Frameworks for MEDiation}

There have been several recent attempts in the Australian context to identify a set of unifying ethical principles to guide mediation practice. ${ }^{15}$ One such attempt is the work of Rachael Field. In a series of arguments, Field calls for an abandonment of neutrality as misrepresenting the role of mediators, particularly in relation to addressing issues of imbalances of power and hence of substantive fairness. ${ }^{16}$ Field advances a contextual ethical paradigm for practice, centralising party self-determination as

13 See Julie MacFarlane, 'Mediating Ethically: The Limits of Codes of Conduct and the Potential of a Reflective Practice Model' (2002) 40 Osgoode Hall Law Journal 49, 49 where the author argues that every mediators intervention involves an ethical decision.

14 Discussion is limited to the Australian context given a focus on the NMAS in Australia and the limits of space.

15 For notable international approaches see MacFarlane, above n 13; Ellen Waldman, 'Values, Models, and Codes' in Ellen Waldman (ed), Mediation Ethics: Cases and Commentaries 1 (Wiley, 2011).

16 Rachael Field, 'Rethinking Mediation Ethics: A Contextual Method to Support Party Self-Determination' (2011) 22(1) Australasian Dispute Resolution Journal 8, 9; see also Rachael Field, 'Exploring the Potential of Contextual Ethics in Mediation' in Reid Mortensen, Francesca Bartlett and Kieran Tranter (eds), Alternative Perspectives on Lawyers and Legal Ethics: Reimagining the Profession (2011) 158-198. 
the normative and categorical aim of practice. ${ }^{17}$ She proposes five guiding principles for the practice of a contextual ethical method in mediation: a thorough contextual analysis of the dispute and the parties; use of a framework of informed consent; adoption of a relational and caring ethic; adherence to the principle that mediators do not impose decisions and hence to do so would be unethical; and an overarching justification for situational action that supports party self-determination. ${ }^{18}$

Crowe articulates a model of mediation ethics drawing on moral psychology, which sees ethical judgement as a practical skill developed by repeated exposure to situational contexts. ${ }^{19}$ Crowe's model has three stated characteristics. It is situational rather than rule-oriented, emphasising the practice guides principle. It is diachronic rather than synchronic, emphasising the development of organic guidelines rather than timeless rules. Thirdly, the model is community-oriented, emphasising a community of practice, rather an individualistic endeavour. Crowe's model further acknowledges the professional nature of mediation practice, its unique contribution as a profession and the diversity of practice approaches and models.

Hardy and Rundle argue that open-ended contextual approaches can be too open-ended and fluid and therefore lack appropriate guidelines for practitioners. ${ }^{20}$ They apply a model of ethical decision-making developed by McAuliffe and Chenoweth for social work practice, ${ }^{21}$ to mediation. The model is described as 'an inclusive model of ethical decision-making'. ${ }^{22}$ It combines recognition of four foundational principles underwriting a series of steps for ethical decision-making. The authors of the model note that ethical decision-making in social work is defined as 'the process of critical reflection, evaluation and judgement through which a practitioner resolves ethical issues, problems and dilemmas'. ${ }^{23}$ The foundational principles, or platforms, they identify are accountability, critical reflection, cultural sensitivity and consultation. ${ }^{24}$

Ojelabi and Sourdin propose a values-based approach to mediation based upon a platform of core values, namely, freedom, justice, equality and peace. ${ }^{25}$ The authors argue that these core values can be

17 Field, Rethinking Mediation Ethics', above n 16, 9.

18 Ibid 10-15.

19 Jonathan Crowe, 'Ethics and the Mediation Community' (2015) 26 Australasian Dispute Resolution Journal 20.

20 Samantha Hardy and Olivia Rundle, 'Applying the Inclusive Model of Ethical Decision-making to Mediation' (2012) 19 James Cook University Law Review 70.

21 Donna McAuliffe and Leslie Chenoweth, 'Leave No Stone Unturned: The Inclusive Model of Ethical Decision-making' (2008) 2 (1) Ethics and Social Welfare 38.

22 Hardy and Rundle, above n 20, 70.

23 Ibid, 49 citing Australian Association of Social Work (AASW), Code of Ethics (Union Offset, 2nd ed, 2010).

24 Hardy and Rundle, above n 20, 42-43.

25 Lola Akin Ojelabi and Tania Sourdin, 'Using a Values-based Approach in Mediation' (2011) 22 Australasian Dispute Resolution Journal 258. 
translated into practice through the use of a framework for decisionmaking and action called the ERSR approach, signifying education, recognition, support and resolution. ${ }^{26}$ Noone and Ojelabi propose an access to justice approach to the measurement of the quality of justice in mediation. ${ }^{27}$ The authors examine access to justice principles developed by the Commonwealth Government Access to Justice Taskforce and suggest how they could be applied to mediation. The principles they identify are accessibility, appropriateness, equity, efficiency and effectiveness. ${ }^{28}$

Another approach has been to look at the ethical codes of different professions. For example, Wolski has presented a thorough analysis of voluntary codes of conduct for lawyers as representatives of their clients in mediation against a background of the requirements of ethical practice for lawyers generally. ${ }^{29}$ Litaba has examined professional codes of conduct for social workers, psychologists and lawyers in an investigation of principles for the ethical practice of family dispute resolution practitioners under the Family Law Act 1975 (Cth). ${ }^{30}$

These varying approaches to mediation ethics draw upon differing perspectives emphasising or combining legal, socio-behavioural and or philosophical vantage points. Each is an attempt to grapple with the interrelated questions of what ethical principles should guide the mediation profession as a whole (for example, justice, equity and accountability) and with that, what principles should guide actual instances of practice (for example, those drawn from a community of practice, critical reflection, an ethic of care and cultural sensitivity). For the broader question of what guides the profession, the principle of participant selfdetermination has been retained and centralised in the revised NMAS. ${ }^{31}$ Ethical issues for mediation include what self-determination means and how it can be furthered in mediation. Waldman identifies party autonomy (or self-determination), procedural fairness and substantive fairness as three central ethical principles and issues for mediation practice. ${ }^{32}$ The relationship between these three principles is the focus of the next part of discussion.

26 Ibid.

27 Mary Anne Noone and Lola Akin Ojelabi, 'Ensuring Access to Justice in Mediation in the Civil Justice System' (2014) 40(2) Monash University Law Review 561.

28 Ibid.

29 Bobette Wolski, 'On Mediation, Legal Representatives and Advocates' (2015) 38(1) UNSW Law Journal 5.

30 Oyiela Litaba, 'Developing Ethical Practice as a Family Dispute Resolution Practitioner' (2013) 24 Australasian Dispute Resolution Journal 36.

31 NMAS, above nn 5-6.

32 Waldman, above $\mathrm{n} 15$. 


\section{Ethical Issues in Mediation}

Self-determination is described as a primary objective ${ }^{33}$ and core value of mediation practice. ${ }^{34}$ Empirical research evidences mediators' adoption of this principle as central to their practice. ${ }^{35}$ Field describes self-determination as the normative and categorical aim of practice. ${ }^{36}$ As noted above, understanding of the self-determination of participants has been included as an ethical requirement of practice in recent revisions to the NMAS. ${ }^{37}$ Lichtenstein defines self-determination as 'the individual's right and ability to make decisions and take actions to follow those decisions through. ${ }^{38}$ Self-determination is not however unequivocally defined in the mediation literature. ${ }^{39}$ It is associated with a range of meanings. ${ }^{40}$ Self-determination is, for example, differently constructed across different models of mediation.

Lichtenstein's definition is associated with the facilitative model, which is reflected in the NMAS. The NMAS defines mediation as a process that supports the self-determination of participants and in which participants, with the support of a mediator, reach and make their own decisions. ${ }^{41} \mathrm{~A}$ central aim of the transformative model is 'empowerment', pursued in relationship to the other party's 'recognition' and given the broader societal aim of the advanced moral growth of citizens. ${ }^{42}$ In the narrative paradigm individual decision-making is given a social context through identification of a social justice agenda. The relationship of the individual to society is given a particular focus with less emphasis on the meeting of individualised needs. In Winslade and Monk's narrative model, personal agency is identified. ${ }^{43}$ In Cobb's storytelling model, celebration

33 James R Coben, 'Gollum Meet Smeagol: A Schizophrenic Rumination on Mediator Values Beyond Self-determination and Neutrality' (2004) 5(2) Cardoza Journal of Conflict Resolution 65, 65.

34 Dale Bagshaw 'Mediating Family Disputes in Statutory Settings (1995) 48(4) Australian Social Work 3, 3; see Boulle, above n 2, 65-67; Douglas, 'Mediator Neutrality', above n 10, 148-149.

35 Douglas, 'Neutrality, Self-Determination', above n 11; Mary Anne Noone and Lola Akin Ojelabi, 'Ethical Challenges for Mediators around the Globe: An Australian Perspective' (2014) 14 Washington University Journal of Law and Policy 145.

36 Field, Rethinking Mediation Ethics', above n 16, 9; see also Noone and Akin Ojelabi, 'Ethical Challenges', above n 35, 165-168.

37 NMAS, above $\mathrm{n} 5$.

38 Marsha Lichtenstein, 'Mediation and Feminism: Common Values and Challenges' (2000) 18(1) Mediation Quarterly 19, 21.

39 Coben, above n 33, 66.

40 Nancy A Welsh, 'The Thinning Vision of Self-determination in Court-Connected Mediation: The Inevitable Price of Institutionalization?' (2001) 6 Harvard Negotiation Law Review 1, 15-18.

$41 \quad$ NMAS above n 5, Pt 111; NMAS, above n 3, cl 2.2 (f) (emphasis added).

42 Robert A Baruch and Joseph P Folger, The Promise of Mediation: Responding to Conflict Through Empowerment and Recognition (Jossey-Bass, 1994) 2.

43 Winslade and Monk, above n 11, 50-51. 
of personal responsibility and reciprocity are depicted as conducive to a sense of community, further identified as a desirable outcome. ${ }^{44}$

Constructions of self-determination in transformative and narrative models draw attention to the fact that the self-determination of individual parties necessarily occurs in a social context. Like the neutrality of the mediator, self-determination of the participants can never be absolute. The parties pursue their needs and interests in the context of their relationship. Hence each party's capacity to be self-determining is necessarily circumscribed by the same capacity of the other party. ${ }^{45}$ Field's use of the phrase 'relational self-determination' captures this reality. ${ }^{46}$ Furthermore, mediation occurs within wider social contexts including institutional and regulatory contexts. These contexts impose limits on the ability of participants to be entirely self-determining. Family dispute resolution provides a clear example, in which the best interests of the child circumscribe the parties' interests. ${ }^{47}$ The institutionalised use of court-connected mediation is another example. ${ }^{48}$ Here the outcome may be self-determined, but attendance is prescribed rather than voluntary, and therefore not selfdetermined. ${ }^{49}$ The issue of whether and how participants ought to receive legal advice, in order to give informed consent to any agreement, ${ }^{50}$ points to the context of mediation within a broader justice system that reflects community standards as to rights and obligations. What justice means in mediation is, however, contested..$^{51}$ This is due, in part, to differing views as to whether mediation's object is to ensure substantive fairness or only procedural fairness. ${ }^{52}$

According to the traditional view, mediators' control of the process limits their role to ensuring procedural fairness. Control of the process was traditionally said to ensure substantive fairness because it ensured the self-determination of the parties. ${ }^{53}$ However, critique of the mediator's claimed neutral role has challenged these assumptions. Research and practice critique have established that the mediator's process interventions do have an impact on the content and outcome of mediation. ${ }^{54}$ Hence the distinction between process and content or outcome cannot be abso-

44 Sara Cobb, 'Dialogue and the Practice of Law and Spiritual Values: Creating Scared Space: Toward a Second-Generation Dispute Resolution Practice' (2001) 28 Fordham Urban Law Journal 1017, 1032-1033.

45 Douglas, 'Mediatory Neutrality', above n 10, 151; Boulle, Mediation, 2nd ed, above n 2,86 .

46 Field, 'Rethinking Mediation Ethics', above n 16, 10.

47 Family Law Act 1975 (Cth) s 69ZN. See Boulle, Mediation, 2nd ed, above n 2, 409.

48 See Boulle, Mediation, 2nd ed, above n 2, 395-396.

49 Ibid 65-66.

50 Noone and Akin Ojelabi, 'Ethical Challenges', above n 35, 155.

51 Ibid 152-158.

52 Ibid.

53 See Douglas, 'Neutrality, Self-Determination', above n 11, 23-24; Field, 'Mediation Ethics in Australia', above n 12, 42.

54 See Astor, 'Rethinking Neutrality' Parts 1 and 2, above n 4. 
lute. ${ }^{55}$ This is a view consistent with the social constructionist worldview that guides transformative and narrative models. ${ }^{56}$ Research has also suggested that interventions are not value free and that mediators can and do subtly dispose parties towards their own preferred outcomes. In response to this dilemma, reflective practice and mindfulness are advocated in order to limit if not eliminate the impact of mediators' bias. ${ }^{57}$

Two particular critiques of mediator neutrality extend understanding of mediation as a whole. One, already noted above, is that like neutrality, the self-determination of parties and the distinction between the process of mediation and its content or outcome can never be absolute. The other is that mediators and mediation cannot claim to be neutral in the sense of being value free. ${ }^{58}$ Mediation's primary value is promoting the selfdetermination of participants. Focus on the self-determination of parties creates the presumption that mediators' values should not direct the process. Yet critique of neutrality has exposed the real potential for unjust or inequitable outcomes where one party participates at a disadvantage, which may be evidenced by an imbalance of power, and mediators claim neutrality. ${ }^{59}$ Hence the values of mediation and of mediators become critical in determining if and when to intervene beyond process to achieve substantive fairness. To date there is no consensus among mediators in answer to these questions. ${ }^{60}$

Considerable debate exists about whether mediators have any role in ensuring substantive fairness for the participants. ${ }^{61}$ In a recent empirical study conducted by Noone and Akin Ojelabi, the researchers found that most of the mediators sampled believed they should not be concerned with the substantive fairness of a mediated outcome. ${ }^{62}$ The mediator's role in ensuring procedural fairness is well recognised. ${ }^{63}$ The NMAS includes a requirement under cl 10.1(c)(v) of Pt III that mediators understand ethical principles in relation to: 'safety, procedural fairness and equity in mediation including withdrawing from or terminating the media-

$55 \quad$ See Boulle, Mediation, 2nd ed, above n 2, 29-31.

56 See, for example, Cobb, above n 44, 1029.

57 See Dale Margaret Bagshaw, 'Self Reflexivity and the Reflective Question: Broadening Perspectives in Mediation' (2005) 24(2) The Arbitrator and Mediator 1; Mark Dickinson, 'The Importance of Self Awareness and Self Development to Mediator Effectiveness' (2010) 21 Australasian Dispute Resolution Journal 97; Tom Fisher, 'Who's Minding the Mediator? Mindfulness in Mediation' (2003) 5(10) ADR Bulletin 165; Evan M Rock, 'Mindfulness Mediation, the Cultivation of Awareness, Mediator Neutrality, and the Possibility of Justice' (2006) 6(2) Cardozo Journal of Conflict Resolution 347, 354.

58 See Susan Douglas, 'Questions of Mediator Neutrality and Researcher Objectivity: Examining Reflexivity as a Response' (2009) Australasian Dispute Resolution Journal 56, 57.

59 See Astor, 'Rethinking Neutrality' Parts 1 and 2, above n 2; Field, 'Mediation Ethics in Australia', above n 12.

60 See Noone and Akin Ojelabi, 'Ethical Challenges', above n 35.

61 Ibid 152-158, 179-182.

62 Ibid 180.

63 Ibid 166-168, 186. 
tion process' ${ }^{64}$ Clause 7 of the NMAS sets out principles of procedural fairness ${ }^{65}$ and impartiality as standards for practice. Clause 7 requires mediators to provide an opportunity for participants to be heard ${ }^{66}$ and to have adequate time and opportunity to be properly informed. ${ }^{67}$ It also requires mediators to avoid or disclose grounds of bias or conflicts of interest to the parties. ${ }^{68}$ Clause 7 requires mediators to support participants to reach agreements freely and voluntarily with informed consent and without undue influence. ${ }^{69}$

Although the principle of neutrality has been omitted from the revised NMAS, the principle of impartiality has been retained. Clause 7 provides that a 'mediator must conduct the mediation in a fair, equitable and impartial way, without favouritism or bias in act or omission. ${ }^{70}$ Under cl 10.1(c)(vi) mediators are required to demonstrate understanding of 'impartiality including the avoidance of conflicts of interest. ${ }^{71}$ Scholars have observed that impartiality is a generally accepted synonym for neutrality. ${ }^{72}$ Given the removal of any reference to neutrality in the NMAS, it becomes necessary to distinguish these two concepts.

This author has argued that both neutrality and impartiality address issues of real and potential bias in mediation, which can be limited but not eliminated. ${ }^{73}$ Based upon that analysis, and in the absence of neutrality, impartiality can be understood to mean, inter alia:

(1) Avoidance of conflicts of interest, qualified by rules of disclosure and consent; and consistent with the common law conflict rule and extending to requirements not to misuse information or position.

(2) Impartiality in relation to both parties; achieved by limiting the intrusion of bias due to mediators' personal situatedness, or their personal prejudices, preconceptions, preferences and persuasions.

(3) Impartiality as between the parties; achieved, by not taking sides, avoiding favouritism and by being even-handed.

$64 \quad$ NMAS, above n 1, cl 10.1(c)(vi) (emphasis added).

65 NMAS, above $\mathrm{n} 1, \mathrm{cl} 7$. Reflecting the rules of natural justice, viz, the hearing rule, the no evidence rule and the rule against bias.

66 NMAS, above n 1, cl 7.5.

67 Ibid, cl 7.6.

68 Ibid, cl 7.2 and 7.3; reflecting the rules of natural justice.

69 Ibid, cl 7.4.

$70 \quad$ Ibid, $\mathrm{cl} 7.1$.

71 Ibid, cl 10(1)(c)(vi).

72 Astor, 'Rethinking Neutrality - Part 1', above n 4, 76-77; Astor, 'Mediator Neutrality', above n 7, 222; Astor and Chinkin, above n 2, 150; Boulle, Mediation, 2nd ed, above n 2, 32-33; Rock, above n 57, 354-355; Field, 'Mediation Ethics in Australia', above $\mathrm{n} 12,49-56$ in which the author considers neutrality in a broad sense to incorporate notions of impartiality.

73 Susan Douglas, 'Constructions of Neutrality in Mediation' (2012) 23 Australasian Dispute Resolution Journal 80; The distinction between impartiality in relation to both parties and as between parties is made by Astor, 'Rethinking Neutrality', Parts 1 and 2 , above $\mathrm{n} 4$. 
Elsewhere, the author has argued that similar constructions of impartiality are synonymous with neutrality. ${ }^{74}$ They are arguable however without reference to neutrality and are consistent with the context of meaning in the NMAS, which refers to the conflict rule and 'impartiality, without favouritism or bias'. Importantly they are distinguishable from neutrality where neutrality is understood as an absolute requirement and a value free position.

Scholars have proposed that neutrality and self-determination can be understood as related concepts. Boulle notes, for example, that:

$[\mathrm{M}]$ ediator neutrality is the other side of the self-determination principle, in that the mediator is disinterested in the mediated outcome and is not responsible for imposing his or her own standards of fairness or appropriateness. ${ }^{75}$

As Astor argues, 'party control is, in a sense, the other side of the coin of mediator neutrality'. ${ }^{76}$ This author has argued that mediator neutrality and the self-determination of participants are grounded in the relationship between mediator and parties, and can be understood as relational concepts mediated by a postmodern construction of power. ${ }^{77}$ In the absence of neutrality, it is proposed that impartiality depicts the attitude or stance of the mediator in his/her relationship with participants. It is argued that the relationship between mediators and participants is marked at one end by the mediator's ethic of impartiality and at the other by mediation's ethic of self-determination for the participants. As an ethic for mediation, impartiality needs to be understood in relation to, or in the context of, the ethic of self-determination.

Being impartial in mediation means more than not having a vested interest, or personal view that affects the process, or being even-handed (that is, the three meanings given above). It also means acting to facilitate the parties' chosen outcomes. ${ }^{78}$ In adjudication impartiality furthers an unbiased application of law to the facts in reaching a decision. By contrast, in mediation impartiality acts to further the participants' own decisionmaking. When understood in relation to self-determination, impartiality points to the necessity of a client-centred practice. Client-centred practice originated with the work of Carl Rogers in counselling and social work. ${ }^{79}$ It has been adopted by other professions, ${ }^{80}$ and is consistent with the

$74 \quad$ Douglas, 'Constructions of Neutrality', above $\mathrm{n} 73$.

75 Boulle, Mediation, 2nd ed, above n 2, 67.

76 Astor, 'Rethinking Neutrality - 2', above n 4, 145.

77 Douglas, 'Neutrality, Self-Determination', above n 11, 151-153.

78 Extending an argument that neutrality and self-determination can be understood as related concepts; See Douglas above n 10; Susan Douglas, Mediator Neutrality: A Model for Understanding Practice (unpublished PhD thesis, University of Southern California, 2010).

79 Carl R Rogers, Client-centered therapy: its current practice, implications and theory (Constable, first published 1951, 2003 ed).

80 See, for example, Thelma Sumsion, Client-centred Practice in Occupational Therapy: A Guide to Implementation (Churchill Livingston, 1999). 
requirement to act according to a client's instructions. ${ }^{81}$ Taylor captures this necessity when she describes self-determination as the "hallmark and most central value for mediators", necessitating the "absolute requirement that mediators take their mandate from the clients". ${ }^{82}$

The NMAS requires that mediators demonstrate an understanding of professional conduct. ${ }^{83}$ They 'must adhere to the ethical code or standards prescribed by the professional organisation or association of which they are a member or by whom they are employed. ${ }^{84}$ In what follows the centrality of trust in professional relationships and in mediation is examined.

\section{Mediation and Professional Relationships}

The introduction of the NMAS in 2008 was a milestone in the establishment of mediation as a profession in its own right in Australia. The NMAS provides a unifying system of accreditation and practice standards, but remains a voluntary system. It overlaps with other accreditation systems and practice codes for dispute resolution in Australia. ${ }^{85}$ The NMAS acknowledges that mediators may be members of other professions and, as noted, requires their adherence to the ethical code or standards of such professions. Every professional relationship is a relationship of trust and confidence. In an argument for the recognition of mediation as an emergent profession in Australia, Field identifies a number of elements that identify a profession, one of which is holding 'public office'. ${ }^{86}$ According to this element mediation satisfies the character of a profession by identifying mediators as holding positions of trust and a warrant of authority that has the purpose of serving others. ${ }^{87}$

Commentators identify trust as an important element in mediation. ${ }^{88}$ Participants' trust in the mediator has been identified as critical to success

81 See Queensland Law Society, Guide to Client Care: Communication and Service (24 September 2014) <www.qls.com.au/Knowledge_centre/Practising_resources/ Client_Care_Guide>.

82 Alison Taylor, 'Concepts of Neutrality in Family Mediation: Context, Ethics, Influence, and Transformative Process' 14(3) Mediation Quarterly 215, 230.

83 NMAS, above n 1, cl 10.1(c)(ii).

84 Ibid.

85 See, for example, Resolution Institute, Information on Accreditation Through the Resolution Institute (previously LEADR and IAMA) <www.resolution.institute/ qualifications/mediation>; Boulle, Mediation, 3rd ed, above n 8, 486-493.

86 Rachael Field, 'A Mediation Profession in Australia: An Improved Framework for Mediation Ethics' (2007) 18(3) Australasian Dispute Resolution Journal 178, 182; see also Boulle, Mediation, 3rd ed, above n 8, 397-400.

87 Field, 'A Mediation Profession in Australia', above n 86, 182 citing FC De Coste, 'Towards a Comprehensive Theory of Professional Responsibility' (2001) 50 University of New Brunswick Law Journal 109, 117.

88 Laurence Boulle, Mediation: Skills and Techniques (Butterworths, 2001) 41-42; Stephen Goldberg, 'The Secrets of Successful Mediators' (2005) 21(3) Negotiation Journal 364; Andrew H Kydd, 'When Can Mediators Build Trust?' (2006) 100(3) American Political Science Review 449; Christopher Moore, The Mediation Process: Practical Strategies for Resolving Conflict (Jossey-Bass, 3rd ed, 2003) 191-194. 
in mediation; 89 and trust between the parties has been evidenced as a significant factor in successful negotiations. ${ }^{90}$ Moore defines trust as 'a person's capacity to depend on or place confidence in the truthfulness or accuracy of another's statements or behaviour' ${ }^{91}$ Boulle defines trust as 'one person's willingness to believe, to be open to, and to take risks with, another person'. ${ }^{92}$ Boulle identifies a number of techniques that a mediator can use to encourage the parties' trust in both the mediator and the process. He lists the following suggestions for mediators:

(1) affirming their credentials as mediators and dispute resolvers;

(2) showing respect and concern for the parties;

(3) establishing a personal rapport with the parties;

(4) using active listening skills and acknowledging the parties' concerns; and

(5) being impartial and even-handed in the conduct of the process. ${ }^{93}$

Affirming a mediator's credentials means acknowledging their expertise. According to Haynes, the professed expertise of the mediator produces an automatic imbalance of power with parties. ${ }^{94}$ Boulle argues that an imbalance in these circumstances can be employed in developing a positive relationship of trust. Showing respect for parties means acknowledging their autonomy and acts as a reminder of the role of the mediator in fostering that autonomy.

Establishing rapport, actively listening and acknowledging concern are skills that foster engagement with parties. Professional engagement requires an objective stance. Professional objectivity is generally understood to mean limiting the intrusion of subjective bias. It includes emotional detachment. Emotional detachment is a dimension of impartiality in the second sense identified above. It includes circumstances where mediators seek to avoid the impact of their personal emotional responses, as well as opinions and preferences, on the mediation. Emotional detachment does not however have to mean aloofness or lack of feeling, particularly when combined with empathy. Empathy is an emotional response that conveys compassion and understanding and is distinguishable from sympathy, where there is identification with another's feelings. ${ }^{95}$ Empathy is identified as an essential ingredient in relationships of trust. ${ }^{96}$

\footnotetext{
89 Goldberg, above n 88.

90 Kydd, above n 88.

91 Moore, above n 88, 192.

92 Boulle, Mediation: Skills and Techniques, above n 88, 41-42 (emphasis omitted).

93 Ibid.

94 John Haynes, 'Mediation and Therapy: An Alternative View' (1992) 10(1) Mediation Quarterly 21, 23.

95 Gerald Egan, The Skilled Helper: A Problem-management and Opportunitydevelopment Approach to Helping (Cengage Learning, 10th ed, 2014). See also Michael Slote, The Ethics of Care and Empathy (Taylor and Francis, 2007).

96 See David Howe, Empathy: What it is and Why it Matters (Palgrave Macmillan, 2013).
} 
Boulle recognises impartiality (in relation to both parties) and evenhandedness (impartiality as between parties) as significant in fostering trust. In a study conducted by Poitras, impartiality was found to be the most significant variable in developing a relationship of trust between mediators and parties. The study found that partiality, or appearing to take sides, was enough to 'shatter trust'. ${ }^{97}$ Research shows that elements of trust, impartiality, empathy and rapport are all significantly interconnected in the relationship between mediator and participants. In a study by Goldberg more than 75 per cent of the mediators sampled attributed their success in mediation (measured by settlements) to their ability to develop rapport with the parties, described as 'a relationship of understanding, empathy and trust'. ${ }^{98}$

Authority, in the definition of a profession referred to above, represents legitimised power. The power exercised by mediators is a function of their recognised expertise and the place of mediation within institutionalised systems of recognition and accountability. Authority comes from professional, organisational and statutory contexts recognised by the community. The NMAS serves as a framework for a professional system of accountability for mediators, albeit a voluntary system. The NMAS also articulates the minimal measures of expertise across knowledge, skills and ethical understanding expected of an accredited mediator. A mediator's role is described as using 'the knowledge, skills and ethical principles ... of the NMAS to assist participants to make their own decisions in relation to disputes, conflicts or differences among them.' ${ }^{99}$ Authority, expertise and institutional recognition enable participants to have confidence in the professional conduct of mediators.

Serving others represents a professional stance in relation to those for whom a professional employs her expertise. Here objectivity in professional practice involves not only an approach that seeks to limit the impact of personal subjectivity but, more crucially, it signals an approach that is 'other focussed', ${ }^{100}$ or client-centred, or as identified by Crowe, as an 'other orientation'. ${ }^{101}$ Client-centred practice is not peculiar to mediation, but it is clearly consistent with the aim of party self-determination.

Having established that the relationship between mediator and participants has the character of a relationship of trust, in which participants derive confidence that mediators will serve the participants' interests rather than their own, further consideration can be given to what principles properly guide ethical conduct by mediators within that relationship. In the discussion to follow, principles associated with fiduciary and therapeutic relationships are examined for their application to mediation practice. These two relationships are chosen in

97 Jean Poitras, 'What Makes Parties Trust Mediators?' (2009) 21(3) Negotiation Journal 307, 321.

98 Goldberg, above n 88, 366.

99 NMAS, above n 1, Pt I, 2.

100 Douglas, Mediator Neutrality - PhD Thesis, above n 78, 100.

101 Crowe, above n 19. 
acknowledgement of the legal and socio-behavioural influences that have shaped mediation practice.

\section{Mediation and Fiduciary Relationships}

Fiduciary relationships are quintessentially relationships of trust in which the fiduciary is expected to be 'other focused,' or 'other orientated. A fiduciary 'is a person who is expected to act in the interests of another person. Fiduciaries cannot use their knowledge or position to benefit themselves rather than the person on whose behalf the fiduciary is required to act.'102 Mediators were required to understand the nature of fiduciary obligations under the NMAS 2008. ${ }^{103}$ This requirement has been replaced by the broader requirement to understand professional conduct. ${ }^{104}$ The character of fiduciary relationships can be applied to mediation. Consequently principles associated with fiduciary relationships can be employed to guide ethical practice in mediation.

The hallmarks of fiduciary relationships are reflected in mediation. Fiduciary relationships are said to arise where one party is in a position of trust in relation to another. ${ }^{105}$ A broad test was enunciated by the High Court in Hospital Products Ltd v United States Surgical Corporation. ${ }^{106}$ According to that decision, a fiduciary relationship arises where a putative fiduciary gives an undertaking, or agrees to act for or on behalf of or in the interests of another person, in the exercise of power or discretion, which will affect in a legal or practical sense the interest of that other person.

Applying the test from the Hospital Products Case mediation, the principle of party self-determination and the mediator's role in facilitating that self-determination is an undertaking to act for, or on behalf of the interests of others, namely the parties. The requirement to act in the interests of another in the exercise of power is a feature of the mediator's relationship with the parties. This element, when applied to mediation, enables acknowledgment of the mediator's exercise of power in relation to the parties. Furthermore, applying this fiduciary requirement to the exercise of mediator power provides a clear principle for the exercise of that power, namely, that it be exercised in the interests of parties and not the mediator. The mediator's exercise of power will affect the interests of parties at least in a practical sense and hence satisfy the final requirement of the High Court's test. Agreements in mediation may or may not be legally enforceable, but practical implications do flow from the parties' experience of mediation and from any agreements reached.

102 Pamela Hanrahan, Ian Ramsay and Geoff Stapledon, Commercial Applications of Company Law (Oxford University Press, 17th ed, 2016) 196.

103 NMAS 2007, above $\mathrm{n} 3, \mathrm{cl} 7(\mathrm{c})(\mathrm{v})$.

104 NMAS, above n 1, cl 10.1(c)(ii); reasons for this change have not been published.

105 Sitesh Bhojani, 'Professionals' Fiduciary Relationships - An ACCC View' (2003)

Proctor 22, 22.

106 (1984) 156 CLR 41 ('Hospital Products Case'). 
There are a number of duties implied by law into fiduciary relationships, including the duties to act for a proper purpose, to act in good faith and in the best interests of the other, and to avoid conflicts of interest. ${ }^{107}$ Acting for a proper purpose in mediation means acting to promote the self-determination of parties, and therefore to provide and promote opportunities for participants to reach their own decisions. Acting in the best interests of parties in mediation is consistent with the core principle of promoting party self-determination. As noted, neutrality and the distinction between process and content limited mediators to assessing the parties' best interests in terms of procedural fairness. The concept of fiduciary relationship permits recognition that mediators will influence the content and outcome of a dispute. It acknowledges the fact of that influence and gives guidance as to its proper scope by requiring that it be exercised in the parties' best interests.

A core indicator of the best interests of the parties is the opportunity to reach their own decisions, to be self-determining as between them. This is the core imperative guiding the practice of mediation. It is what mediation espouses as being in the best interests of the parties. Beyond this core measure, the parties' best interests will vary according to various factors, including the interests of the parties as individuals, cultural contexts, the nature of the dispute and its cultural, organisational and statutory contexts. The collective best interests of the parties will arguably be co-incident with community standards reflected in statutory contexts. Minimal standards of substantive fairness reflected in law have a place as a prescriptive context for mediation because they address tensions in promoting the self-determination of both parties where their aims are in conflict and or where one party is negotiating at a recognisable disadvantage. ${ }^{108}$ Here, acknowledgement can be given to the reality that mediators make assessments that determine their interventions, and that the strategies they adopt have an impact on the course of the mediation requiring them to be accountable. The duty to act in the best interests of parties does not provide a ready reckoner for determining proper intervention in every case. However, it does allow for assessment based upon both procedural and substantive fairness because it is not limited to issues of process.

Fiduciaries have a duty to avoid conflicts of interest. Similar to the bias rule in adjudication, a fiduciary is required to disclose any actual or apparent conflicts of interest. ${ }^{109}$ As noted above, this duty is reflected in the NMAS standards. The duty in law extends to a requirement not to misuse information or position, the first of which is contained in the NMAS. ${ }^{110}$ The requirement of impartiality as between the parties distinguishes mediation from some other fiduciary relationships because it points to

107 Hanrahan, Ramsay and Stapledon, above n 102. Additional duties include to retain discretions and to act with reasonable care and diligence.

108 For example, as in family dispute resolution where a child's best interests are paramount or where domestic violence is an issue.

109 Hanrahan, Ramsay and Stapledon, above n 102.

110 NMAS, above n $1, \mathrm{cl} 8.2$. 
the need for mediators to balance, as far as possible, the requirements of fairness as between the parties. For example, while in the lawyer-client relationship, the lawyer is required to advocate for the interests of their client as against another party, in mediation the mediator must act in the best interests of both parties. Acting for more than one party is recognised in legal relationships outside the lawyer-client relationship. For example, a trustee may need to look to the interests of more than one beneficiary. When acting for the interests of a company, a director, or board of directors, may need to consider differing, possibly conflicting interests of members. ${ }^{111}$ In mediation it is particularly important to distinguish the role of the mediator (including a lawyer mediator) from that of a lawyer by emphasising the mediator's role in acting in the best interests of both parties. Acting in the best interests of both parties means to facilitate and balance, as far as possible, each party's opportunity to reach his/her own decisions. ${ }^{112}$ The role of the mediator is not dissimilar in this sense to the role of a therapist in furthering the self-determination of each client in joint therapy. While a mediator does not give legal advice or provide counselling or therapy, mediators like lawyers and therapists have a duty to act in their clients' best interests, although the contexts and detail of that duty are different. Discussion now turns to other principles, those deriving from therapeutic relationships, that have relevance for ethical mediation practice.

\section{Mediation and Therapeutic Relationships}

Therapeutic relationships are necessarily relationships of trust, in which the patient, or client, must feel sufficiently trusting of the therapist to expose frailty, vulnerability and the need for help. Notions of procedural and substantive fairness are not centrally associated with a therapeutic perspective. Yet principles associated with therapeutic relationships can extend our understanding of ethical mediation practice by extending constructions of fairness.

While ongoing therapeutic relationships do not occur in mediation, there is some similarity with the therapeutic dynamic. Thus, the mediator maintains a measure of detachment from the detail and turmoil of the parties' conflict and he or she does not enter into the dispute by taking sides or rendering a decision about the conflict. At the same time, the mediator must actively engage with the parties by building rapport, actively listening to the content of their dispute, maintaining an alert interest and intervening in ways that provide opportunities for the parties to move towards resolution.

111 For example, interest in profit as against environmental protection.

112 Assessing possible interventions by asking 'what is in the best interests of the participants?' was recommended to the author at a recent mediator professional development program; and was used in the context of furthering the participants' own decision-making. 
As an aid towards conflict resolution, attention is given in the mediation literature to the opportunity provided for parties to hear themselves and to advance any insight gained as a result. Goodhardt, Fisher and Moloney argue that this opportunity is a core component of transformative mediation, which they further argue has a therapeutic equivalent in Rogerian theory. ${ }^{113}$ One of three basic interventions that the transformative mediation holds in common with Rogerian therapy is 'reflection'. Reflection, according to Goodhardt et al has three purposes:

(1) it allows a party to be heard and know that they have been heard;

(2) it allows a party to hear their own words in the same way as the other party has heard them, thus enabling insight into the impact of their words on another; and

(3) it gives parties a chance to refine or clarify what they have said as a result of insight and reflection. ${ }^{114}$

The opportunity to hear oneself extends the right to be heard, a core principle of procedural fairness. This extension is consistent with the aim of participant self-determination. The opportunity to hear oneself is potentially an aid in reviewing and revising existing understanding both of oneself and the other party. Hearing oneself can reveal unconscious yet driving emotions, thoughts and impulses that can block constructive conflict resolution. Hearing oneself can facilitate clarity around what is an acceptable outcome, what interests can be compromised and what interests are paramount.

The role of the therapist was traditionally understood as one of neutral intervener, whose task was to facilitate the self-actualisation of the patient. One criticism of this approach has been that it fails to acknowledge the fact that the therapist's value system influences interpretation of the patient's situation. Therapists, like mediators, cannot be said to be neutral in any absolute sense. From an examination of modernist, Freudian conceptions of neutrality through to postmodern intersubjective and relational orientations, Baker, a psychoanalyst, proposes an alternative in his construction of a 'neutral position'. The neutral position, according to Baker, is:

$[\mathrm{N}]$ either a given prescription nor a set of instructions. It does not refer to any action, activity, or behaviour undertaken by the analyst. Neither does it embrace anonymity, non-responsiveness, silence, coldness, aloofness, or disinterest. ${ }^{115}$

The neutral position is essentially an attitude in an interactive, intersubjective space, which places responsibility on the analyst as the 'keeper and conscience' of the process. ${ }^{116}$

113 Ian Goodhardt, Tom Fisher and Lawrie Moloney, 'Transformative Mediation: Assumptions and Practice' (2005) 12(2) Journal of Family Studies 317.

114 Ibid 320.

115 Ronald Baker, 'Finding the Neutral Position: Patient and Analyst Perspectives' (2000) 48(1) Journal of the American Psychoanalytic Association 129, 140.

116 Ibid 148. 
The neutral position advanced by Baker resonates with mediation practice because both the process of therapy and that of mediation have as their purpose the self-determination of participants. Psychotherapy, like mediation, brings professional expertise to the task of facilitating and harnessing participants' own resources in an effort to aid resolution of internal and or external conflict. In keeping, however, with rejection of the concept of neutrality in mediation, Baker's neutral position can be substituted by the 'other focus' of the mediator. Baker lists a number of ethical principles required of this 'other focus', which have immediate applicability for mediation. According to Baker, the therapist:

(1) does not take sides in considering the patient's conflicts;

(2) does not impose values on the patient but instead accepts the patient's values;

(3) does not try unilaterally to make things happen and is nondirective, eschewing out of principle any attempt to influence the patient toward change;

(4) is non-judgemental towards the patient and those in the patient's life;

(5) subordinates his or her personality to the analytical task; and

(6) repudiates any adversarial notion of the analytic relationship. ${ }^{117}$

By substituting 'parties' for 'patient' and 'mediator' for 'therapist', each principle can be applied to the relationship between mediator and parties. Not taking sides, the first principle, is the literal, popular meaning of impartiality. It encompasses the absence of bias or vested interest, and alignment with either party. Impartiality is clearly encompassed by the next four characteristics, according to which the mediator does not intrude by imposing his or her own values on parties, does not direct the parties towards any outcome constructed by the mediator, does not judge the parties in terms of 'right' or 'wrong' and, while contributing to the process in an individually unique way, aligns that input according the principles attached to the mediator's role rather than manifesting an individual personality. Furthermore, each of these characteristics emphasises the primacy given to the parties' interests and their capacities to be selfdetermining, through accepting parties' values, avoiding influencing them towards change, adopting a non-judgemental attitude and subordinating the mediator's personality to the task of furthering the parties' interests.

Adopting a non-judgemental attitude is a core skill in therapeutic interventions adopted and adapted in mediation. ${ }^{118}$ It means communicating no opinion as to whether either party is right or wrong, no opinion as to whether the parties' behaviour is blameworthy or exemplary, and no opinion as to whether the parties' values and opinions are acceptable or not. It may be that, according to the context in which mediation occurs, particularly a statutory setting, certain consequences flow for the parties

117 Ibid 140 .

118 Ruth Charlton and MS Dewdney, The Mediator's Handbook: Skills and Strategies for Practitioners (LawBook Co, 2nd ed, 2004) 297. 
from particular attitudes, values and behaviours. However, the 'other focus' of the mediator requires that his or her personal judgements do not intrude into the encounter. Adopting a non-judgemental attitude is consistent with Baker's sixth and final principle, namely, repudiating any adversarial conception of the therapeutic relationship. This is immediately relevant to mediation as an alternative to adversarial processes. It points to a minimisation of an adversarial approach between parties, as well as between the parties and the mediator.

\section{Conclusion}

Traditionally neutrality in mediation meant that a mediator was neutral as to the content and outcome of mediation but in control of the process. In theory, the mediator's control of the process ensured procedural fairness; and the participants' control of the content and outcome ensured substantive fairness, which was equated with participants' opportunity to reach their own decisions, or to be self-determining.

In reality, research has revealed that the distinction between process and content is not absolute, that a mediator cannot be absolutely neutral, and that each participant cannot be absolutely self-determining. In view of these realities, mediation's claims to fairness are significantly jeopardised.

Abandonment of neutrality as an ethical principle in the revised NMAS signals rejection of an absolute approach and acknowledgement that mediation and mediators are not value free. Self-determination remains the central ethical principle of practice. Fostering self-determination is mediation's proper purpose. Recognising that self-determination cannot be achieved without taking into account the relative positions of participants opens the door for consideration of issues of substantive fairness. Traditional reliance, however, on the distinction between process and content is neither adequate nor sufficient to reframe the role of the mediator with issues of substantive justice in mind. This is because reliance on that distinction effectively limits mediators to addressing issues of procedural fairness only.

As an alternative, the relationship of trust between mediator and participants is proposed as a suitable and defensible organising principle for ethical practice in mediation. As an organising principle, the relationship of trust has immediate generality and appeal across models of practice and across professional identities within practice. Relationships represent a fluid and dynamic construction of the interaction between mediator and parties and are not limited to carving up the encounter into elements of process, content and outcome. Relationships of trust are clearly established as integral to mediation's character and measures of its success. A relationship of trust is furthermore central to professional relationships and signals the 'other focus' of the professional in applying her expertise in the service of her client.

The particular character of the relationship of trust between mediators and participants can be constructed by looking to the nature 
of professional relationships and the socio-legal influences on mediation's establishment as a profession. In substitution for neutrality, impartiality marks the 'other focus' of the mediator in relation to participants. Impartiality is construed as a principle that seeks to limit rather than absolutely eliminate bias. Impartiality also means ensuring that ownership of the dispute and its resolution remains with the parties, in other words, that mediation is client-centred.

The 'other focus' of the mediator means acting in the best interests of parties consistent with the principle of self-determination. Impartiality translates the mediator's 'other focus' into practice. Drawing on the nature of professional relationships of trust, it means an objective stance in which the impact of the personal situatedness of the mediator is minimised. Drawing on the nature of fiduciary relationships, impartiality means exercising power for a proper purpose, namely, furthering the selfdetermination of participants. It also means avoiding conflicts of interest and acting impartiality as between the parties. Drawing on therapeutic relationships, impartiality means not taking sides, not directing participants towards any outcome, not imposing personal values, not imposing any judgement (as an outcome or as an attitude), avoiding an adversarial approach and putting aside one's personality in furtherance of the task at hand. Furthermore, by adding the opportunity to hear oneself (central to therapeutic relationships) to the opportunity to be heard in mediation, procedural fairness is extended and shaped to fit mediation practice.

The principle of acting in the best interests of participants, as a requirement of relationships of trust, can be substituted for mediators' attempts to determine their interventions according to process but not content. As a general rule, the best interests of participants will coincide with optimal opportunities to be self-determining. Exceptions will occur where an optimal opportunity for one participant to be self-determining results in manifest unfairness for the other. In such circumstances objective measures of substantive fairness have a place in balancing the interests as between parties, and in balancing the interests of parties in relation to standards of the community/society of which they are a part. Employing relationships of trust as a framework for ethical mediation practice, in substitution for reliance on the distinction between process and content, enables issues of substantive fairness to be openly recognised and debated. It remains for society at large and the mediation community as officers of the public good to articulate what standards of substantive fairness properly apply. 